\title{
El Contrato de Aparcería
}

\author{
por el Dr. LUSS ALBERTO GAZZOLO.
}

Catedrático de Derecho Rural y de Derecho Administrativo (P. U. C.)

Bajo la denominación de "contratos tipo asociativo" quedan incluídas aquellas combinaciones caracterizadas por una estructura asociativa $y$ función colaboradora, entre el capital inmobiliario y el trabajo. Estos contratos son esencialmente: la Aparcería, la Colonia o Colonato aparciario y el Yanaconaje. Nos ocuparemos en este artículo del contrato de Aparcería.

LA APARCERIA. Es el tipo mós perfecto de participación del trabajo en la empresa agraria; ha tenido una notable función $\mathrm{y}$ un indiscutible valor en la historia económica y social de muchos países, tales como en los países Balcónicos, Grecia, España, Italia y Rusia. El término Aparcería deriva de la voz latina: Adpartiarius ( $A d=a-$ pars, partis $=$ parte) es decir a la parte o al partir.

La Aparcería puede definirse como el contrato por el cual una parte (concedente, propietario, usufructuario, arrendatario, enfiteuta) se asocia con otra (aparcero) para cultivar una parcela de terreno dividiéndose los productos y las utilidades. El concedente, $\alpha$ quien muchas veces le concierne la dirección de la empresa, aporta el capital inmobiliario y parte del ejercicio o agrario; el aparcero en cambio, además de aportar el resto del capital agrario, entrega en forma esencial el propio trabajo y el de su familiá. En esta combinación de personas económicas de la empresa es, por consiguiente, decisivo el carácter de comunidad de riesgo.

Durante mucho tiempo se sostuvo que la aparcería no era otra cosa que un contrato de locación de cosas o de obras; esta tendencia sostenida por Colin et Capitant y Baudry - Lacantinerie es la corriente que ha primado en Francia y que la asimila $\alpha$ un arrendamiento. Pero, como bien dice Zulueta "...lo que diferencia esencialmente la. Aparcería del arrendamiento es la distribución de los productos por partes alícuotas o iguales Y nó mediante un cánoǹ fijo" (1).

(1) Derecho Agrario. - Zulueta. 
Otra tendencia es $\bar{l} \alpha$ de considerarla como una sociedad, pues en ella se encuentran casi todos los elementos que caracterizan a la sociedad o sea aportes de ambas partes, el interés común y la participación en las utilidades y en las pérdidas. Desde luego se trata de una sociedad de tipo sui generis, que se diferencia precisamente de la sociedad comercial, por numerosos aspectos propios tales como: el carácter exclusivamente bilateral, la limitación de la libertad que se haya encaminada a un solo fin rigurosamente especificado. Con todo, a pesar de que la aparcería se asemeja mucho a la sociedad, no se puede confundir con ella, por las siguientes saltantes diferencias:

1.-La Aparcería es un contrato necesariamente bilateral, en cambio la sociedad es un convenio plurilateral, es decir, se puede celebrar entre más de dos personas. Podrá agüirse, al respecto, que también en el contrato de aparcería pueden participar más de dos personas y, en efecto muchas veces sucede así cuando el aparcero trabaja en unión con su familia; pero aún en este caso la doctrina actual admite que el contrato es bilateral, ya que el aparcero y los componentes de su familia constituyen un centro único de intereses, vale decir una sola parte.

2.-En la Sociedad, la gestión es regida en todo momento por la voluntad común de todos los socios; en la aparcería la dirección se atribuye sólo al concedente quien imparte las directivas al aparcero y sus familiares.

3.- En el contrato de Sociedad surge una personalidad distinta de la de cada uno de los socios, los bienes aportados son de la sociedad y nó de los socios. La sociedad es una persona jurídica, la aparcería no es persona jurídica.

4.- En toda sociedad las ganancias y las pérdidas se soportan entre los socios en igual proporción; ésto no sucede en cambio en la aparcería, puesto que, en el caso de pérdida de la cosecha, evidentemente que el más afectado es el aparecero que ha trabajado en vano y nó el dueño de la tierra o concedente que las sigue conservando.

De lo expuesto llegamos a la conclusión que la Aparcería no es una sociedad, ni tampoco un arrendamiento. Por eso algunos tratadistas la consideran dentro de los límites de los contratos innominados; este último, es el criterio de Lafaille. Creemos nosotros que es un contrato especial e independiente, pese a que la ley 10885 la equipara a la sociedad y la ley 10841 la involucra dentro de las prescripciones del arrendamiento.

Como bien dice el profesor Guillermo Garbarini Islas en su obra de Derecho Rural Argentino: "Del hecho de que la aparcería sea una sociedad - una locación surgen consecuencias importantes, tales por ejemplo, las que se refieren a la terminación de la misma; si es sociedad corresponderá liquidarlas, y el plazo que habrá que darse al colono será el necesario para ello, en tanto que si es locación, tendrá este los plazos que le concede el Código Civil". Igualmente, agrega otra consecuencia importante: es la concerniente a la muerte de una de las partes contratantes, ya que mientras la sociedad se disuelve por ella, la locación continúa. 
Las ventajas económicas de la Aparcería se concretan esencialmente en la colaboración de las personas económicas de la empresa, colaboración provechosa porque los contratantes al estar cointeresados en el éxito de la operación, ponen todo el cuidado necesario para que la producción sea mayor. Esta prerrogativa, que en el pasado tuvo gran valor y eficacia, actualmente se va esfumando, porque la aparcería también ha sido envuelta en los accesos de las luchas clasistas y políticas.

En suma la aparcería beneficia al propietario de la tierra como al aparcero. Al propietario porque sus utilidades son mayores y sobre todo porque no lo aleja de las actividades del campo, puesto que tiene que vigilar $\mathrm{y}$ controlar los trabajos que se ejecutan en sus tierras. Al aparcero, porque éste, como generalmente no tiene capital, encuentra en la aparcería una ayuda que le permite indudablemente trabajar el campo, en mejores condiciones económias que el simple arrendatario.

La aparcería ha sido objeto de críticas de parte de economistas y sociólogos. De modo especial se le imputa la demasiada rigidez contractual, que contrasta con la diversa fertilidad de los terrenos en los cuales se aplica y la lentitud para adecuarse al progreso técnico. Estos dos inconvenientes no son, al menos en la teoría, del todo infundados. Sin embargo, se debe reflexionar, en cuanto concierne $\alpha$ la cristalización del sistema que, con la introducción de ciertos pactos accesorios $y$ oportunas modificaciones, pueden en gran parte reducirse tales inconvenientes.

Señala el Dr. César Augusto Reinaga, que, "desde el punto de vista social" la aparcería constituye una espectativa permanente para el trabajador agrícola de elevarse en la escala social. No sólo el aparcero sino también el yanacona se inician en la marcha de una explotación y se ha bitúan en los cálculos del mercado aprovechando los consejos del terrateniente hacendado; así muchas veces con un capital en un principio restringido, uno y otro acceden a dirigir una explotación" (2). Participamos también nosotros de la opinión, que la aparcería puede constituir el primer peldaño que tiene el bracero agrícola para convertirse en propietario.

SUJETOS DEL CONTRATO.-Los sujetos de la relación aparcera son: el Concedente y el Aparcero. El concedente que aporta el goce de una extensión de tierras, como también los implementos, utensilios, semillas, yuntas, tractores, etc., para el trabajo de la tierra. En algunos contratos el aporte de las semillas, yuntas, abonos, etc., se hacen por partes iguales con el aparcero.

El concedente puede ser, como ya lo hemos manifestado, poseedor del fundo, usufructuario, enfiteura o también propietario, pudiendo figurar también como parte de la relación aparcera el gran arrendatario que esté en el goce de un predio rústico.

La otra parte contratante es el aparcero, le más de las veces en unión con su familia. En este caso, sostiene Bassanelli: "lo que se busca es que el trabajo lo asuma una unidad familiar, de modo que la armonía entre

(2) "El Indio y la Tiecra en Mariátegui", pág. 11. 
los trabajadores repose sobre vínculos afectuosos y exista una jerarquía de parentela, en la cual el poder del jefe se cristaliza en el padre". (3) En este caso quien contrata con el concedente es el Jefe de Farmilia que representa a todos los componentes de la misma.

La persona del Aparcero, es pues un elemento esencial, tanto si interviene en forma particular o en compañía de su familia; por esta razón, se considera a la Aparcería como un contrato intuitu personae, como lo exigen las obligaciones de hacer que emanon del acto y la colaboración de carácter continuado entre los contratantes, que presuponen confianza personal.

El aporte del aparcero es su trabajo y el de los componentes de su familia, en tal forma que asegure el cultivo del fundo o el ejercicio de las actividades conexas al mismo. En algunos tipos de este contrato aporta también, en forma proporcional, semillas e implementos de trabajo agrícola.

El Fundo.- El fundo o predio rústico es el objeto del contrato de aparcería agrícola. Los terratenientes sostienen al respecto que, donde falta éste y la casa, no hay Aparcería porque la esencia del contrato es el trabajo, sobre la base familiar y ésta reside, se alimenta y recibe todo lo necegario del fundo. Así es támbién en nuestra legislación, ya que el contrato que estudiamos tiene como base la tierra, la que por sus diversas dimensiones puede ajustarse a la ley 10841 ó a la ley 10885 y en ésta última *e establece, a tenor de lo dispuesto en el artículo 15, que el concedente estŕ obligado a proporcionar al aparcero casa-habitación ubicada en su parcela o en lugar adecuado, a voluntad de las partes; señalando al mismo tiempo que si el concedente no cumpliera con proporcionar casa, el aparcero podrá construirla hasta por un valor de Mil soles, suma que será abonable a tarsación al término del contrato.

Clases de Aparcería.- Dentro de la actividad agraria se establecen varias clases de aparcería; para el tratadista C. F. Cerrillo, las modalidades esenciales son dos:

"1:-La Aparcería sencilla, en la que el propietario sólo aporta la tierra Y sus accesorios, pero sin tener intervención alguna en el cultivo. Esta es la forma más extendida, y se diferencia tan solo del arrendamiento en que mientras en éste la renta es fija, en aquella el aparcero entrega una participación de los productos".

"20-También se puede convenir que ambos contratantes disfruten del uso o goce de la tinca o de algunos de sus aprovechamientos. Por tanto, los interesados intervendrían conjuntamente on el cultivo, $\mathrm{Y}$ aportarían también en común, los abonos, las simientes, los jornales, etc., partiéndose los productos con arreglo a la proporción" (4). Pero evidentemente existe otra forma más que es la APARCERIA GANADERA, la que a su vez admite diversas modalidades.

(3) Corso di Diritto Agrario - pág. 153. - Milano, 1946.

(4) Las Aparcerías y sus formularios" - pág. 17. 
La Aparcería ganadera fué considerada como una locación de cosas, mientras en la actualidad la mayoría de los tratadistas la consideran como un contrato asociativo. Esta modalidad consiste en el contrato por el cual las partes se asocian para la crianza y explotación de cierta cantidad de ganado y para el ejercicio de las actividades conexas, con la finalidad de repartirse el aumento de cabezas de ganado y los productos derivdos según las cláusulas contractuales o los usos del lugar. Existen tres clases de aparcería ganadera:

a.-la Simple, cuando el concedente entrega el ganado sin transferirlo al aparcero y éste aporta su trabajo;

b. -la Compuesta que consiste en que el ganado es aportado por las partes; $Y$

c.-la Aparcería ganadera con otorgamiento de pastos, por medio de la cual el concedente entrega el ganado y el aparcero aporta el terreno para el pastoréo, de tal manera que al concedente le toca la dirección de la sociedad y al aparcero no le queda sino el simple control de la gestión.

Naturaimente que, además de estas principales formas, existen en la práctica otras muchas, con relaciones asociativas mixtas, pero que pueden reducirse $\alpha$ dos categorías definidas y diferenciadas por el más estrecho criterio económico social. Pertenecen a la primera categoría las que tienden a coordinar y armonizar la disponibilidad del ganado con la disponibilidad del pasto, asociando a los que carecen de pasto para su propio ganado con quienes carecen de ganado para la utilización de sus propios pastos. Se consideran en la segunda categoría a aquellos que tienden a asociar a quienes disponen de ganado $y$ de pasto, o de uno de estos medios, con otros que aportan el trabajo necesario $y$, también, eventualmente los otros medios que falten.

\section{Ia Aparcería en el Perú.}

No existe, desde el punto de vista jurídico, como contrato independiente. En efecto el C. C. vigente no se refiere a esta institución dentro del rubro de la contratación, como una figura Sui generis, sino asimilada $\alpha$ un arrendamiento. La costumbre en nuestro medio, en combio, in considera como una sociedad de carácter civil. Esta falta de precisión en la figura que comentamos, ha dado origen $\alpha$ interpretaciones muy desiguales en nuestros Tribunales, los que algunas veces se han pronunciado porque la Aparcería cae bajo las prescripciones del contrato de arrendamiento; $y$ en otras han aplicado la tendencia que deben regirse por los dispositivos do la Sociedad Civil.

En realidad, en nuestro país, la figura tiene más puntos de contacto con la Sociedad que con el arrendamiento. El Aparcero, "compañero o partidario" actúa como un socio industrial de la empresa, poniendo su trabajo, mientras que el dueño o concedente de la tierra, el socio capitalista, lo proporciona la semilla, abono, yuntas o tractores para el trabajo. Convienen 
así mismo en dividirse las utilidades, generalmente un $50 \%$ para el concedente. Ha sido práctica normal en estos tratos que el aparcero está obligado a vender su parte de la producción. al propietario, desde luego a un precio más bajo que el que tiene el producto en el mercado.

Si acudimos al "Diccionario de la Legislación Peruana" de F. García Calderón, constataremos que la "Aparcería es el trato o convenio de los que van a la parte en alguna granjería, principalmente en la administración de tierrs $\mathrm{Y}$, cria de ganado". De este concepto, que ha sido recogido de los usos agrícolas del país se deduce que existen dos tipos de aparcería: uno netamente agrícola y otro de carácter sustancialmente ganadero. En la definición acotada del Diccionario, notamos que el elemento esencial de la definición es: "principalmente en la administración de tierras", vale decir el concepto de la administración, vocablo, que según el sentir de Henry Capitant, es la acción de: "manejar, dirigir un bien, un conjunto de bienes - un patrimonio", concepto que desemboca necesariamente en la idea de: sociedad.

El contrato de aparcería en la actualidad, y desde el punto de vista legal, se desplaza dentro de la órbita de las leyes 10841 y 10885 llamada de Yanaconaje, pues la segunda parte del artículo $1^{\circ}$ de dicha ley establece que: "...el contrato en todo lo que no esté dispuesto en la presente ley. queda regulado por las normas del Código Civil referentes al contrato de locación y conducción o de Sociedad, según el caso y comprende $\alpha$ los colonos, partidarios, compañeros..."-El artículo $10^{\circ}$ de la indicada Ley completa el concepto al señalar que, "en los contratos de Yanaconaje, en los que el yanaconizante celebra compañía con el yanacón, dirigiendo los trabajos y aportando la habilitación necesaria para todos los gastos de cultivo como semillas, herramientas, abonos, insecticidas, etc., inclusive el jornal del yanacón y sus familiares, las utilidades se dividirón en partes iguales, después de deducirse la habilitación y el importe del arriendo, que seró fijado con arreglo al artículo $8^{\circ}$ de esta ley".

Para la ley 10885 el contrato de Yanaconaje puede cristalizarse en uno de aparcería. En este último caso al yanacón se le denomina: "Aparcero", "Partidario", Socio, Compañero, Camayo o Concertado, según los diferentes lugares de nuestro territorio. En la Sierra del Perú a la institución se le: denomina "Waqui" e igual nombre tiene en Bolivia. Apunta el doctor M. Julio Delgado que: "el Waqui es una sociedad mixta de capital y trabajo; teniendo dos modalidades: agrícola y ganadera. La primera consiste en que uno de los socios pone el terreno. si es propietario, o paga el arrendamiento con el trabajo si es arrendire; mientras que el otro aporta su trabajo y los gastos de explotación; llegada la fecha de la cosecha se efectúa la división por partes iguales. La semilla corre por cuenta del socio que contribuye con la tierra y la cosecha es recogida por ambos".

"El Waqui ganadero consiste, en que uno de ellos aporta como capital un animal madre ya sea vaca, oveja, llama, pacocha, chancho, etc., mientras que el otro se preocupa en cuidar y mantener al animal, hasta el estado de que las crias sean separables de la madre. En aquellos casos en que sólo hay una cría, según el convenio la cria primera es para el dueño 
del animal madre y la posterior para el que da la alimentación y cuida. El reparto de la cria o ganancia se hace también por partes iguales" (5).

Es necesario resaltar que las Comunidades de Indígenas en nuestro país han logrado consuetudinariamente los siguientes tipos de Aparcería:

A.-Se suministra por partes iguales la semilla $\mathrm{y}$ se reparten por mitades las utilidades. En cambio si sólo el aparcero puso la semilla éste se llevará la paja después de finalizada la campaña agrícola.

B.-El aparcero presta determinados servicios en la campaña de maíz. a cambio de que el propietario le dé la paja para su ganado.

C. - La tierra es dividida en dos mitades; elige el dueño su parte y el aparcero trabaja las dos mitades. La cosecha es para el dueño en su parte y de igual manerra para el aparcero en su respectivo lote. La paja en cambio es para el aparcero que pone la semilla, pero los instrumentos de labranza son del propietario.

D. -El concedente aporta la tierra. El aparcero se ocupa de efectuar la limpieza y de deshierbarlo, efectuando la labor de roce, dejando a la tierra lista para la siembra. Efectuada la siembra el aparcero trabaja a mitad con el dueño.

Volviendo a las leyes que rigen este contrato, haremos hincapié en que la 1085, llamada Ley de Yanaconaje, no sólo ha dado muerte desde el punto de vista jurídico a esta Institución sino también a la Aparcería, ya que no mantiene la esencia del contrato tal como es concebido por los usos y por la doctrina. En efecto, según el art. 10 de la ley acotada, el concedente dividirá en partes iguales lás utilidades, después de deducirse las habilitaciones y el importe del arriendo; quiere decir que el contrato de aparcería ha tomado un carácter accesorio del principal y único contrato que es el del arrendamiento. Primero se cobrará la merced conductiva y las habilitaciones, después se dividirón las utilidades lo que evidentemente es un atentado, repetimos, contra la esencia del contrato mismo.

En cuanto al reparto de las utilidades, la ley establece la distribución. en partes iguales. En cambio, el Reglamento de la misma, en el artículo $8^{\circ}$. señala que las utilidades se dividirán en la proporción equitativa que convinieron las partes. Esta prescripción Reglamentaria ha puesto fin a la figura del Mediero o partidario, puesto que todo el que contrate al amparo de la ley y del Reglamento pertinente no irá al partir de frutos.

Apunta la ley en cuestión que el Contrato de Aparcería debe hacerse necesariamente por escrito, debiendo contener las siguientes estipulaciones:

a.-Nombre, apellidos, domicilio, edad, estado civil de los contratantes $y$ lugar y fecha del contrato;

b.-La ubicación, órea $\mathrm{y}$ linderos de la tierra materia del contrato;

c. - Si el concedente es propietario o arrendatario de las tierras que aporta;

d.-Los aportes que deberá hacer el concedente, ademós de la tierra $y$

(5) "Organización de la Propiedad Rural en la Sierra".-Pág. 40. 
del agua, como semillas, bueyes, etc., según la costumbre de la región; $y$

e.-La proporción en que se dividirán o repartirán las utilidades, y el tiempo de duración del contrato.

En cuanto a las habilitaciones que reciba el aparcero, éstas se computarán siempre en dinero y "los abonos, semillas, herramientas y todo lo que el concedente entregue al aparcero, le será proporcionado al precio de costo, más el interés del 12\% anual al rebatir". (Art. 11\%-Ley 10885).

La duración del contrato de aparcería será fijada por las partes; pero en ningún caso el aparcero podrá ser despedido antes de que se cumplan tres años del contrato. (Segunda parte del art. 6-Ley 10885).

Nuestra Legislación no prevé el problema que se puede presentar acerca de la dirección de la explotación, punto que reviste vital importancia por constituir la aparcería una sociedad. Aun cuando las opiniones al respecto están divididas, sosteniendo algunas legislaciones que la dirección de la empresa le concierne al concedente y otras al Aparcero, creemos noso. tros que este punto debe quedar expresamente especificado en el convenio y si no se especifica se entenderá que la fiscalización corresponde al concedente, tratando en la medida de lo posible de excluir que el poder de dirección se base en una relación de jerarquía. De otro Jado, el derecho de control y fiscalización, en nuestro medio, se deduce de la aplicación de la prenda agrícola que debe gravar el aparcero en favor del concedente de conformidad con lo dispuesto en el artículo 12 de la ley 10885.

En cuanto a las obligaciones principales de los contratantes, éstas pueden cristalizarse de la siguiente manera:

a.-Obligaciones del concedente; $y$

b.-Ob:igaciones del aparcero o comunero.

OBLIGACIONES DEL CONCEDENTE.-Aparte de las obligaciones que conciernen a todo locador, en virtud de que este contrato en nuestro medio también se rige por las prescripciones del arrendamiento, las principales obliqaciones del concedente son:

1.-Entrega de un lote de tierras al aparcero:

2.- Obligación de garantizar el pacífico goce de las tierras, vale decir, defender el uso de la cosa contra un tercero que quiera o pretenda ejercer algún derecho sobre ella.

3.-La obligación de Abstención.- Porque para que en el aparcero surja la posibilidad del goce, es necesario que se le ponga en estado de completa libertad respecto del lote de tierras. Las obligaciones de tolerar $\mathrm{y}$ del no uso son típicas de la locación; pero también las encontramos en la aparcería, aunque con caracteres y limitaciones propias. La contraposición entre aquello que es prohibido al locador y consentido al arrendatario tiende a desaparecer en la cparcería, porqué la figura del deudor del goce hacia la sociedod $y$ la figura del socio están sobrepuestas en la persona del concedente

4.--Obliqación de mantener las tierras en estado de servir al uso convenido.

5. - Obligación de entregar la casa para el aparcero y su familia; y, 
6. -La obligación de anticipar todo lo necesario para el sustento alimentario del aparcero y su familia. - Esta es precisamente una de las características más notables de la aparcería, y una de las manifestaciones de espíritu patriarcal, que aún anima la relación aparcera y que nuestra ley vigente tiende a aminorar, al permitir que el concedente cobre intereses por los anticipos y habilitaciones.

OBLIGACIONES DEL APARCERO.-La principal obligación del aparcero es la prestación de sus servicios y los de los componentes de su tamilia. El trabajo debe encuadrarse dentro del que corresponda a las necesidades del cultivo y a las reglas o usos de una buena técnica agro-pecuaria. Nuestra ley 10885, en la parte final del artículo $10^{\circ}$, al mencionar el trabajo del aparcero o yanacón, nos habla del jornal que debe percibir tanto él, como los componentes de su familia, salario que no podrá ser inferior al fijado por el Poder Ejecutivo en cada región. Esto significa convertir al aparcero en un simple operario, que lo aleja una vez más de la típica figura de la Aparcería que nos dá la práctica y la doctrina. En efecto, en ningún lugar del mundo, el contrato de Aparcería contiene normas relativas a salario, horario de trabajo, vacaciones $u$ otras que contrasten con la naturaleza de las relaciones aparceras, ya que la cuota parte de los frutos que le toca al aparcero, no participa de los caracteres de un salario y por consiguiente no está sujeto a las prescripciones generales del trabajo. En cambio, entre nosotros, sucede lo contrario, ya que el aparcero está sujeto a un salario, $\alpha$ tenor de lo dispuesto por el mencionado artículo $10^{\circ}$ de la acotada ley .

Entre otras obligaciones del aparcero, podemos mencionar las siguientes:

1.-Obligación de custodia; y

2. - Obligación respecto a los productos.

Obligación de custodia. - El aparcero debe custodiar las tierras y mantenerlas en constante estado de productividad. Aquí, precisamente, pueden aplicarse los principios vigentes en materia de locación, tales como el que el conductor responde por la pérdida y el deterioro de la cosa, aún derivados del incendio, a no ser que pruebe que provengan de caso fortuito o fuerza mayor.

Obligaciones respecto a los productos. - El aparcero tiene como obligación cosechar los frutos; y ésta precisamente es una operación que esiá catalogada entre los trabajos del cultivo. Pero antes de proceder al recojo de los frutos debe obtener el consentimiento del concedente. De lo cosechado el aparcero es propietario por cuota, es decir según la proporción estipulada entre las fartes. Este es uno de los principios en que se sustenta el contrato de aparcería; todos los productos, pues, deben dividirse incluyéndose entre ellos a los que han crecido en forma espontánea, excepto los árboles muertos o derribados cuya propiedad es exclusiva del concedente, a no ser que éstos hayan sido destinados al servicio del fundo o tierras objeto del contrato.

\section{EXTINCION DEL CONTRATO.}

Las causas de extinción propias de este contrato son:

a.-El receso ad tempus, vale decir por conclusión del término de dura- 
ción que fijaron las partes, sin que seq̣ necesario el aviso de despedida del concedente al aparcero, en aplicación del inciso $1^{\circ}$ del art. 1531 del C.C.

b.-Extinción por justos motivos.-Lo que quiere decir que cada una de las partes puede pedir la rescisión del contrato, cuando se verifican hechos tales que no consientan la prosecución de la relación aparcerc, tales como cuando el aparcero dispone de los frutos en su provecho y no paga las habilitaciones recibidas o cuando abandona el cultivo de las tierras, así como también cuando el aparcero es vencido en juicio sobre el derecho que tenía, o cuando transfiere el derecho de goce del fundo contra pacto expreso o sin consentimiento del concedente.

c.-Otra de las causas de extinción es la muerte del aparcero, nó la muerte del concedente. De esta premisa se deduce que, el contrato es intuitu personae sólo en lo que concierne al aparcero y su familia ya que si se medita en el asunto, constataremos que el aparcero tiene mós interés en el fundo que el propio concedente, como se comprueba con el ejemplo frecuente de familias que, no obstante la anualidad del contrato, viven por generaciones en el mismo fundo.

Respecto a la muerte del aparcero, es necesario apuntar que en este caso es de aplicación el inciso $3^{\circ}$ del art. 1531 del C.C. que establece que la muerte pone fin al contrato, si los herederos del aparcero comunican que no pueden continuar al frente de los trabajos agrícolas.

LA APARCERIA EN NUESTRA JURISPRUDENCIA.-Nuestros Tribunales también han dado aplicaciones dispares, respecto a la Aparcería, pues en la mayoría de los casos hon asimilado la institución que tratamos a un arrendamiento, aún cuando también existen Ejecutorias que la consideran bajo las prescripciones de la sociedad, tal por ejemplo la que se publicó en el "Diario Judicial", de Agosto de 1947, que establece:

"Es improcedente la demanda Ejecutiva por falta de pago de arren-: damientos si se trata de contrato de aparcería, pudiendo el demandante sólo hacer uso de acciones distintas para el efecto de la fijación de lo producido".

En este expediente, el señor Fiscal de la Corte Suprema, sostuvo que no siendo la aparcería un contrato de arrendamiento, sino de sociedad, no era aplicable el artículo 598 del C. de P. C. - Vemos pues latente, a través de esta ejecutoria, la tendencia que la Aparcería debe considerarse como una sociedad, pero, como lo hemos repetido, es un contrato sui generis, que necesita regularse en forma especial; sin embargo en la exposición de motivos del Proyecto de Ley de Reforma Agraria que acaba de entregar al Ejecutivo la Comisión para la Reforma Agraria, podemos leer con cierta desilución: "que la Aparcería no ha sido tratada independientemente, sino siguiendo la técnicg de nuestro C. C. que la considera como un arrendamiento a partir de frutos". Este temperamento será una vez más, la ratificación del concepto de que frente a un Perú real, existe un Perú legal. 